\title{
Towards a Three-Dimensional Perspective of Space for Humanizing Hospital Care
}

\author{
Hanneke van der Meide
}

\section{Introduction}

The patient in the bed has almost become an icon for the real patient who is in the computer. I've actually coined a term for that entity in the computer. I call it the iPatient. The iPatient is getting wonderful care all across America. The real patient often wonders, where is everyone? When are they going to come by and explain things to me? Who's in charge? Everybody who enters the healthcare system becomes isolated-it is built into the very infrastructure of the system. And, following from this, we can see that one of the most helpful things we can do to improve the experience of bodily impairment is to reduce that social isolation and vulnerability.

This apt description voiced by the medical doctor Abraham Verghese in a TED Talk expresses a feeling that is palpable in wider society (Verghese 2011). Various scholars have described the alienating effect provoked by being in the hospital or in other care settings. A patient's sense of human belonging is likely to become vulnerable in an institu-

\section{H. van der Meide $(\bowtie)$}

University of Humanistic Studies, Utrecht, The Netherlands 
tional context such as a hospital (Williams and Irurita 2004). This comes on top of the already disconcerting effect of the disease itself (Alzhén 2011; Svenaeus 2011). Illness has essentially been characterized as an experience of not feeling at home in the world or in one's body (Toombs 2001a). Sveneaus describes the body as uncanny. He draws upon Heidegger's description of illness as unhomelike being-in-the-world, but adds that the body will always remain our body. "The body is alien, yet, at the same time, myself. Although it involves biological processes beyond my control, these processes still belong to me as lived by me" (Svenaeus 2000). In this context, some authors state that features of contemporary healthcare might add extra suffering and leave patients with feelings of discomfort and even pain (Berglund et al. 2012; van Heijst 2011). Suffering can be distinguished from physical pain in that in physical pain, there can still be a sense of meaning and wholeness, while in suffering, people feel disconnected from others and the self (Cassell 2001).

Humanization refers to practices that take the perspectives and values of people who are part of the practice into consideration (Visse 2012). In this chapter I will limit myself to the notion of space and its meaning for the humanization of care. The influence of spatial aspects on patients' well-being is described as crucial for more humanizing care (Galvin and Todres 2013; Norlyk et al. 2013). The notion of lived space is usually introduced referring to "the more" of the physical space: the felt and experiential space (Norlyk et al. 2013). In Europe, over the last decade, a lifeworld awareness has increasingly been applied to healthcare. Care given from a lifeworld perspective could provide important ideas and values that are central to the humanization of healthcare practice. This lifeworld perspective is grounded in phenomenological philosophy, which I will briefly describe in this chapter, followed by an examination of how lived space is understood and illustrated by examples from empirical research. Second, from a care ethical perspective, I will argue for a broader notion of space that better reflects the practice of care. The lifeworld approach remains focused on care as too narrow an interaction between two people, the patient and the healthcare professional. Third, I will explore the three-dimensional perspective of space as described by philosopher and sociologist Henri Lefebvre. His view allows a shift in 
focus from the experiencing subject to social practice and changes the object of analysis when studying the (de)humanization of care.

\section{Phenomenology and Lived Space}

\section{Lifeworld}

Phenomenology refers to a philosophical attitude towards the world. "Phenomenology is the study of human experience and of the way things present themselves to us in and through such experience" (Sokolowski 2000). In contrast to Western scientific thinking, phenomenology aims to bring together polarities such as mind-body, subject-object, individualsocial and feelings-thoughts. The hyphens signify intertwining rather than separation (Finlay 2011). This is why Merleau-Ponty describes phenomenology as a science of ambiguity. There is always ambiguity and, in a sense, indeterminacy, "precisely because we are not capable of disembodied reflection upon our activities, but are involved in an intentional arc that absorbs both our body and our mind" (Merleau-Ponty 1962). Heidegger describes the impossibility of being disconnected from the world by his concept of being-in-the-world. The lifeworld-Lebensweltis the central phenomenological focus and portrays this lived wholeness and inseparability. It denotes a meaningful whole that is both shared and experienced by individuals from their own unique perspective (Heidegger 1998).

The issue of the lifeworld should be understood against the background of the advent of modern science; before then, people simply thought that the world we live in was the only world there was (Sokolowski 2000). The project of phenomenology as started with Edmund Husserl (1859-1938) was to show that the exact, mathematical sciences are founded on the lifeworld and that they are transformations of the experience people directly have of things in the world. Husserl attempted to call to mind that

the lifeworld (...) is always already there, existing in advance for us, the 'ground' of all praxis whether theoretical or extra theoretical. The world is 
pre-given to us (...) not occasionally but always and necessarily as the universal field of all actual and possible praxis, a lifeworld. To live is always to live-in-certainty-of-the word. (Husserl 1970, p. 142)

The lifeworld is the beginning place-flow from which we divide up our experiences into more abstract categories and names (Galvin and Todres 2013). Husserl did not question the value of modern science and his work suggests that there is nothing wrong with concepts and scientific theories as long as they refer to specific experiences and not just to each other. Phenomenology as a research method is directed towards exploring a human experience (a phenomenon) as it is lived through rather than how we conceptualize, theorize or reflect on it.

In recent years, interest in phenomenology has increased in the domain of professional practice (van Manen 2014). While in research primacy is increasingly given to categories, numbers and averages that might obscure the human dimensions (Galvin and Todres 2013), phenomenology can offer "a bridge across the chasm between practice and research" (Finlay 2011). Although not everyone explicitly refers to the phenomenological notion of lifeworld, Dahlberg, Todres and Galvin have done so. These Swedish and British researchers have revisited Husserl's notion of lifeworld and describe in various papers how care led from this perspective could provide important ideas and values that are central to the humanization of healthcare practice. Humanization refers to "those things which make us feel more human" (Galvin and Todres 2013). They define eight philosophically informed dimensions for the humanization of care: insiderness, agency, uniqueness, togetherness, sense-making, sense of personal journey, sense of place and embodiment. The corresponding dimensions of dehumanization are described as: objectification, passivity, homogenization, isolation, loss of meaning, loss of personal journey, sense of dislocation and a reductionist view of the body (Todres et al. 2009). They advocate a perspective of care what they call lifeworld-led care that should be distinguished from patient-led or person-centred healthcare (Dahlberg et al. 2009). Although they appreciate these perspectives that emphasize the agency of patients, they question whether they encompass the kinds of concerns and knowledge of patients. On the one hand, they argue a consumerist and citizen model overly emphasizes personal or collective 
agency and self-authority and underemphasizes patients as "exposed" and "vulnerable." In this way, they are an opposite reductionist version of a medical model that overemphasizes illness and underemphasizes the phenomenon of human agency. They contend that when people become patients, they want to be seen in both their agency and vulnerability and feel unmet by interactions that emphasize one or the other. Because of the space for ambiguity, a phenomenological lifeworld perspective can address both dimensions of human existence.

\section{Lived Space as an Existential of the Lifeworld}

The lifeworld is something both general and individual as we live in a shared world that we experience from our own unique perspective (van Manen 2014). To understand is both to understand something of this unique individual and the shared intersubjective horizons within which any unique experience occurs (Galvin and Todres 2013). Heidegger differentiates between the ontological that refers to the existential preconditions of being human and the ontic, in which there are many uniquely different individual and cultural ways of experiencing such ontological structures. Phenomenological research aims to give snapshots of these ontological structures, acknowledging that they always remain a part of the whole (Hansen 2015). There are at least four ontological structures described by various phenomenological philosophers that pervade the lifeworlds of all human beings, regardless of their historical, cultural or social situatedness. In order to not confuse these fundamental lifeworld themes with the more particular themes (the ontic) of certain human phenomena that are studied in phenomenological research, van Manen describes the fundamental lifeworld themes as "existentials" (van Manen 2014). Ashworth and Ashworth call them fragments to emphasize their interlinking, interpenetrating meanings (Ashworth and Ashworth 2003). Todres et al. use the words "constituents" and "dimensions" (Todres et al. 2007). They all refer to a conceptual framework that can be used in research to describe human experiences in their holistic context. The constituents of the lifeworld most commonly identified are lived time, lived space, lived body and lived intersubjectivity. These four existentials are 
proven to be a helpful guide for reflection in the research process of phenomenological questioning, reflecting and writing (van Manen 2014).

Lived space is thus considered an existential dimension of our lifeworld. Unlike objective space, which refers to dimensions such as length, height and depth, lived space refers to the perceptual experience of space. This lived space is difficult to put into words and yet we know that the space in which we find ourselves affects the way we feel. The huge space of, for example, a train station may make us feel exposed and small, and a nice and cosy restaurant lets us feel at ease. The typical (sterile) air we smell when we enter the hospital can reassure us or instil fear. What this lived space as felt space entails can best be illustrated by examples from research practice.

\section{Example 1: Lived Space for a Person with Alzheimer}

Ashworth and Ashworth describe the lifeworld of a person suffering from Alzheimer's disease in an attempt to focus in a realistic way on what people with dementia have rather than what they lack (Ashworth and Ashworth 2003). In order to care well for a person with dementia, a carer should become an informal phenomenologist and set aside his or her own criteria of truth and reality and suspend the scholarly knowledge of what dementia typifies. Instead, the carer turns his or her attention to the actual activity and talk of the person in order to discover the meanings of that person's lifeworld. They describe how, for a woman with dementia, space no longer radiates around her as the known and familiar or the available-to-be-known. Some spaces may be experienced as boundariless. There are, for example, no constraints of modesty or privacy. The woman in the study is no longer able to rely on space, and a gate or locked doors, for example, do not mean a boundary or threshold. "Naming a space may no longer have the power to reassure - the label may no longer indicate 'here' versus 'there." This boundlessness can present other difficulties. People with dementia often become dizzy and disoriented. This may render some comfortable places awful and some strange places attractive. For the person with dementia, the world is filled with objects that appear as recalcitrant: the sock resists conformity with the foot, and the bracelet stubbornly refuses to fit over her hand. There are situations in which she is caught up in bodily intention, usually situations that call for dexterous 
action. The researchers give the example of a person whose arms are held out for dancing and to which the person with dementia immediately responds.

\section{Example 2: MS and Lived Space}

The philosopher Kay Toombs (2001b), who suffers from multiple sclerosis (MS) herself, describes how, for her, body physical space is oriented space. Points in space do not represent merely objective positions, but rather they mark the varying range of her aims and gestures. The narrow passageway in which she has to move with her wheelchair represents a "restrictive potentiality" for her body requiring a modification of her actions. The dimensions of high and low also vary according to the position of her body. From her wheelchair, the top three shelves in the grocery store are too high to reach. To be a body is therefore to be tied to a certain world. Lived space thus concerns the encounter with an environing world: a world of places, things and situations that have meaning for living and consequently for health.

Linda Finlay describes the lifeworld of a woman in an attempt to elucidate the existential impact of early stage MS (Finlay 2003). She shows how the unity between her body and self can no longer be taken for granted. With her arm desensitized and spatially dislocated, she has to learn how to carry out everyday living tasks in new and unfamiliar ways. She must look at her arm in order to see what "it" is doing. This provokes a sense of bodily alienation. Also, she tries to keep her illness hidden from others; this part of her identity needs to be a secret and only emerges within her personal space when she is alone in bed at night.

\section{Example 3: Lived Space in the Hospital}

In my PhD study, I shadowed older patients during their stay in the hospital. Shadowing is an observational method in which the researcher observes an individual during a relatively long time. Central aspects of the method are the focus on meaning expressed by the whole body, and an extended stay of the researcher in the phenomenal event itself (van der Meide et al. 2013). I have described the essential structure of their experi- 
ences of hospitalization as "feeling an outsider left in uncertainty" (van der Meide et al. 2015). The use of the term "outsider" describes the feeling of "not fitting in" and "not belonging to." The hospital environment plays a constitutive role in this experience and appears as an inhospitable place. The opposite, a hospitable place, is a place where a person feels comfortable, involved in his or her own way and recognized as a person for whom the situation carries meaning.

Although the older patients experience the hospital as safe in certain respects, they do not feel at ease. The proximity of hospital staff provides reassurance that the physical state is being monitored and that help is at hand in case something goes wrong. However, the sense of safety seems strictly limited to their body in a physical sense. The observations show that hospital staff typically enter the room for a specific purpose: for example, to draw back the curtains in the morning, to take a blood pressure measurement or to shower the patient. Most of the conversations between care professionals and the older patient are functionally oriented. I witnessed many moments of self-talk in which the older patients were struggling aloud with their wishes and carefully evaluating them. Having the impression that care professionals are busy ("they continuously walk back and forth") seems to make the older patients reluctant to express their needs. They don't want to be a burden for the nurse. Diffidence about using the hospital button is an example of this ambiguous safety. On the one hand, the older patients know it can be used when nobody is around and help is needed, and on the other hand, they are uncertain about what they should use the bell for. Despite being constantly surrounded by many care professionals, the older patients feel alone when it comes to figuring out how to deal with the situation and much of their concerns and uncertainties remain unexpressed, although they would prefer it otherwise.

\section{Consideration}

What the foregoing shows is that space is not merely experienced from within, but that it has a profound impact on practices in the hospital and 
daily life by determining actions and behaviours. That is due to a number of features of space. Firstly, space shapes and alters identities. The meaning of MS is partly constituted by the space in which a person with MS moves. Also, space may include and exclude. Some people may feel comfortable and at ease in a given space, while others feel lost and alienated. This is eloquently described in the first example of the person with Alzheimer. Finally, space creates possibilities and imposes restrictions. Literal space configures possibilities for movement and action, as we have seen in the example of Toombs. If one is impaired and wheelchair bound, only surfaces that are accessible are conducive to this conveyance. The experiences of the older patients show that lived space is also related to autonomy and that it has relational meanings. The hospital appears as a closed space for older patients, rather than an open space that invites activity and involvement. The patients' worlds are thus not only objectively smaller as they are confined to the hospital bed or a chair but also subjectively contracted.

\section{Space as an Active and Social Process}

\section{Care as a Practice}

Care ethics has stressed the centrality of caring for human life as a practice. Within care ethics, care is not seen as an isolated act or a set of actions that just occurs between the patient and the healthcare professional. Indeed, care is not given in a societal vacuum. Society as such and politics in particular bring intentions and expectations to the matter of care giving, its institutions and its funding (Vosman and Baart, 2011). Since caring always involves power, it is political at every level (Tronto 2010). All kinds of other institutional incentives, such as marketorientation, accountability, cost-reduction and technologization, play an increasing role in the hospital, and consequently have implications for the healthcare professional-patient relationship (Vosman and Baart 2008).

As sociologist Andrew Sayer has noted, the dominant logic of systemic rationality changes the basis of our institutions. "Many of us are all too familiar with the rise of audits and the imposition of standardized proce- 
dures on activities which seem to defy standardization. Supposedly, these provide rational systems for organizing and assessing the performance of individuals and institutions" (Sayer 2011). Consequently, care can be understood as a practice that takes place in a complicated interplay of people, actions, artefacts (taken for granted) modes of knowledge and organizational structures (beyond the hospital as institution). A practice perspective implies that an issue can only be solved to some extent if one takes a sufficiently large perspective (a cut-out) and simultaneously addresses the question at different levels (Baart and Vosman 2015). The cultural anthropologists Gibson and Olarte Sierra show that hospital beds can be understood as spaces that are constituted through meaning and practice as political, socio-economical, cultural and social. The hospital bed might appear as an administrative space, a space of discipline and medical surveillance, but also of self-surveillance (Gibson and Olarte Sierra 2006).

Empirical studies performed from a lifeworld approach are predominantly focusing on the patient perspective. They state that descriptions offered by a lifeworld perspective revealing the experiences of those in need of care can make a difference to the deepening of emphatic understanding in readers and practitioners (Galvin and Todres 2013). The lifeworld perspective approaches care as an interaction between two people: the patient and the healthcare professional. The conceptualization of lifeworld-led healthcare includes an articulation of three dimensions: a philosophy of the person, a view of well-being and not just illness and a philosophy of care that is consistent with this. What is missing is a contextual and political dimension. Karin Dahlberg has emphasized that phenomenology is not studying the individual, but is studying how a particular phenomenon manifests and appears in the lifeworld, and this always already includes the social world (Dahlberg 2006). However, many phenomenological researchers tend to isolate the phenomenon under study from the context it is lived in by focusing too narrowly on individual experiences. This applies in particular to psychologically oriented phenomenological research. The social and political context usually plays an important role at the beginning of the research, in providing a rationale for conducting the study, and at the end, when the results are reflected upon. But throughout the whole research process, such as when 
choosing a particular method, while collecting the data and in the analysis, the context often receives little attention, as the focus remains on the individual experience.

\section{Space as a Social Product}

Henri Lefebvre (1901-1991) was a French philosopher and sociologist engaged with existential ideas (Elden 2004). In his prolific career, Lefebvre wrote more than 60 books and 300 articles covering a wide range of topics. In his work, Lefebvre shows an interest in the dialectic and he tends to work with three terms rather than the dualism of the two. He conceives the three as affecting each other simultaneously, without prioritizing one term over another. Instead of searching for a transcendence, a synthesis or a negation, he studies the continual movement between them. Lefebvre has written about space in The Production of Space (1974/1991). In this book, he argues that space is a social product, or a complex social construct (based on values and the social production of meanings), that affects spatial practices and perceptions. "(Social) space is a (social) product [...]; the space thus produced also serves as a tool of thought and of action [...] In addition to being a means of production it is also a means of control, and hence of domination, of power."

Although his work is complex and not about care practices, some of his insights might be helpful to better understand the meaning of space for humanizing healthcare. Lefebvre criticizes the binary notion of objective and lived space for still starting from the subjectivity of the ego. Lefebvre aims to a materialist version of phenomenology in which the epistemological perspective shifts from the subject that thinks, acts and experiences to the process of social production of thought, action and experience. According to him, space is fundamentally bound up with social reality. Space does not exist "in itself"; it is produced. Lefebvre proceeds from a relational concept of space and views space as a social product. This calls for an analysis that would include the social constellations, power relations and conflicts relevant in each situation. This would also imply the shift of the research perspective from space to processes of its production; the embrace of the multiplicity of spaces that are socially 
produced and made productive in social practices; and the focus on the contradictory, conflictual and, ultimately, political character of the processes of production of space.

How is (social) space then produced? Key to Lefebvre's theory is the view that the production of space can be divided into three dialectically interconnected dimensions: the perceived (perçu), the conceived (conçu) and the lived (vécu). All three concepts denote active and at once individual and social processes.

Human beings do not stand before, or amidst, social space; they do not relate to the space of society as they might to a picture, a show, or a mirror. They know that they have a space and that they are in this space. They do not merely enjoy a vision, a contemplation, a spectacle - for they act and situate themselves in space as active participants. (Lefebvre 1991, p. 294)

The first dimension is the perceived. Evidently, perception depends upon the subject: a patient does not experience the hospital in the same way as a medical doctor. Nevertheless, Lefebvre's attitude towards the phenomenological version of perception is quite sceptical. Therefore, he combines it with the concept of spatial practice in order to show that perception not only takes place in the mind, but that it is based on a concrete, produced materiality. The complex spatial organization of practices shapes perceived spaces in, for example, households, neighbourhoods and in hospitals. This is the physical dimension of space. Second, space cannot be perceived as such without having been conceived in thought previously. It refers to our knowledge of a certain space that is primarily produced by discourses of power and ideology constructed by professionals, researchers, policymakers etc. Space presumes an act of thought that is linked to the production of knowledge. This is the mental dimension of space. The dimension of lived space denotes the world as it is experienced by human beings in the practice of their everyday life. On this point, Lefebvre is unequivocal: the lived, practical experience cannot itself be exhausted through theoretical analysis. There always remains a surplus, a remainder.

Lefebvre's theory of the production of space identifies three moments of production: first, material production; second, the production of 
knowledge; and third, the production of meaning. Space is to be understood in an active sense as an intricate web of relationships that is continuously produced and reproduced. When we approach space as something that is produced, rather than just something that is experienced by individuals, the object of the analysis should consequently be the active process of production.

\section{Conclusion}

What can be gained from such a three-dimensional perspective of space when studying the (de)humanization of hospital care? The Norwegian philosopher Kari Martinsen (2006) has described the hospital as a public house that expresses a common order. This order expresses in its turn that which has been valued in society. She speaks about the battle for the spaces and the tension between the rooms of the hospital as spaces in which to dwell and spaces in which to be disciplined. Dwelling refers to the feeling of belonging and being safe, and it concerns a shared space, while a disciplined space refers to a means of control and domination. In this context, she distinguishes two ways of seeing by the healthcare professional, which she calls the perceiving eye and the recording eye. Perceiving should be seen as a participating way of looking at the other and allows the other, who is often not known, to emerge. Perception is a fundamental openness towards the other, and it is the patient who has the initiative to show what is of importance. In perceiving, there is a unity between the one who perceives and that which is perceived, and it puts the healthcare professional and the patient in a common world. It thus goes deeper than having good communication skills and requires an open attitude on the part of the healthcare professional. Indeed, a good healthcare professional should not only hear what is explicitly asked for but should be sensitive to implicit appeals (Vosman and Baart 2011).

The second way of seeing Martinsen describes is recording. While perceiving occurs within a relation, recording takes place from an outside position. The "eye" of the healthcare professional is then busy with looking for and abstracting common characteristics to organize under an already defined concept of classification. It abstracts from the concrete 
context. The origin of the verb "to diagnose" refers to this analytical scrutiny that abstracts from all the details that might obscure a clear view (van Heijst 2011). Diagnosis means looking through something instead of looking at someone. This leads to a specific understanding of the situation. Evidently, many diagnostic tools and screening instruments have greatly contributed to the progress that medicine has achieved since the seventeenth century. However, we should not ignore some of the consequences of this view, of which one is the nature of space that is produced by such an approach. Over-emphasis on diagnostics and guidelines guides the physical and the mental dimension of space in a certain direction, following the dominant ideology of society and politics. Also, the logic of the market, for example, requires that doctors do not spend any time with the patient that is not being paid for.

An increased interest in the dimension of space in care can be observed. The dominant objective of contemporary hospital architecture is to create a "pleasant and sustaining environment." Hospitals do everything possible to resemble a hospital as little as possible. One may notice this already when one enters the hospital. Although the hospital has always been a public space, this has acquired another connotation in recent years. The ground floor of hospitals increasingly looks like an extension of the city centre, with interior streets and commercial facilities, ATMs, bars and hairdressers. This has been called the "malling" of the hospital (Fiset 2006). Healing architecture draws upon research that shows that environmental elements such as natural light, a view of nature, less noise and subdued colours produce positive patient outcomes and reduce stress. Single-patient rooms not only create a quieter hospital stay and increase privacy but also reduce patient transfers and the risk of infection. A family zone where family members may stay overnight helps patients feel less alone. A quieter environment may also help staff perform their duties with fewer medical errors. In order to determine whether these developments are good examples of humanized care, a thorough analysis is needed. The three-dimensional perspective of space, as described in this paper, may provide a guide for such an analysis and can illuminate care as a practice that is always social and political, but at the same time lived out in the lifeworld. It offers a lens to look at, reflect on and enhance care practices. Also, studying the dynamic interplay between the dimensions enables a better understanding of spatial vulnerability. 


\section{References}

Alzhén, R. (2011). Illness as Unhomelike Being-in-the-World. Phenomenology and Medical Practice. Medicine, Health Care, and Philosophy, 14(3), 323-331. Ashworth, A., \& Ashworth, P. (2003). The Lifeworld as Phenomenon and as Research Heuristic, Exemplified by a Study of the Lifeworld of a Person Suffering Alzheimer's Disease. Journal of Phenomenological Psychology, 34(2), 179-204.

Baart, A., \& Vosman, F. (Eds.). (2015). De Patient Terug van Weggeweest. Werken Aan Menslievende Zorg in Het Ziekenhuis. Amsterdam: SWP.

Berglund, M., Westin, L., Svanström, R., \& Sundler, A. J. (2012). Suffering Caused by Care-Patients' Experiences from Hospital Settings. International Journal of Qualitative Studies on Health and Well-Being, 7, 1-9.

Cassell, E. J. (2001). The Phenomenon of Suffering and Its Relationship to Pain. In S. K. Toombs (Ed.), Handbook of Phenomenology and Medicine (pp. 371-390). Dordrecht: Kluwer Academic Publishers.

Dahlberg, K. (2006). The Individual in the World-The World in the Individual: Towards a Human Science Phenomenology that Includes the Social World. Indo-Pacific Journal of Phenomenology, 6, 1-9.

Dahlberg, K., Todres, L., \& Galvin, K. (2009). Lifeworld-Led Healthcare Is More Than Patient-Led Care: An Existential View of Well-Being. Medicine, Health Care, and Philosophy, 12(3), 265-271.

Elden, S. (2004). Understanding Henri Lefebvre. London: Continuum.

Finlay, L. (2003). The Intertwining of Body, Self and World: A Phenomenological Study of Living with Recently-Diagnosed Multiple Sclerosis. Journal of Phenomenological Psychology, 34(2), 157-178.

Finlay, L. (2011). Phenomenology for Therapists: Researching the Lived World. Oxford: Wiley-Blackwell.

Fiset, M. (2006). Hospitabel Hospitals: Creating a Healing Environment. International Hospital Federation Reference Book. Retrieved from http:// www.fisethospiconsult.com/SCN_0002.pdf

Galvin, K., \& Todres, L. (2013). Caring and Well-Being. A Lifeworld Approach. New York: Routledge.

Gibson, D., \& Olarte Sierra, M. F. (2006). The Hospital Bed as Space. Observations from South Africa and the Netherlands. Medische Antropologie, 18(1), 161-176.

Hansen, F. (2015). The Philosophical Practitioner as Co-researcher. In A. Fatic \& L. Amir (Eds.), Practicing Philosophy (pp. 22-41). Newcastle: Cambridge Scholars Publishing. 
Heidegger, M. (1998). Zijn En Tijd (Being and Time) (M. Wildschut, Trans.). Nijmegen: SUN.

Husserl, E. (1970). The Crisis of European Sciences and Transcendental Phenomenology. An Introduction to Phenomenological Philosophy. Evanston: Northwestern University Press.

Lefebvre, H. (1991). The Production of Space. Oxford: Blackwell.

Martinsen, K. (2006). Care and Vulnerability. Oslo: Akribe.

Merleau-Ponty, M. (1962). Phenomenology of Perception. Abingdon: Routledge. Norlyk, A., Martinsen, B., \& Dahlberg, K. (2013). Getting to Know Patients' Lived Space. Indo-Pacific Journal of Phenomenology, 13(2), 1-12.

Sayer, A. (2011). Why Things Matter to People. Social Science, Values and Ethical Life. Cambridge: Cambridge University Press.

Sokolowski, R. (2000). Introduction to Phenomenology. Cambridge: Cambridge University Press.

Svenaeus, F. (2000). The Body Uncanny-Further Steps Towards a Phenomenology of Illness. Medicine, Health Care, and Philosophy, 3(2), $125-137$.

Svenaeus, F. (2011). Illness as Unhomelike-Being-in-the-World: Heidegger and the Phenomenology of Medicine. Medicine, Health Care, and Philosophy, 14(3), 333-343.

Todres, L., Galvin, K. T., \& Dahlberg, K. (2007). Lifeworld-Led Healthcare: Revisiting a Humanizing Philosophy that Integrates Emerging Trends. Medicine, Health Care, and Philosophy, 10(1), 53-63.

Todres, L., Galvin, K. T., \& Holloway, I. (2009). The Humanization of Healthcare: A Value Framework for Qualitative Research. International Journal of Qualitative Studies on Health and Well-Being, 4(2), 68-77.

Toombs, S. K. (Ed.). (2001a). Handbook of Phenomenology and Medicine. Dordrecht: Kluwer Academic Publishers.

Toombs, S. K. (2001b). Reflections on Bodily Change: The Lived Experience of Disability. In S. K. Toomb (Ed.), Handbook of Phenomenology and Medicine (pp. 247-262). Dordrecht: Kluwer Academic Publishers.

Tronto, J. C. (2010). Creating Caring Institutions: Politics, Plurality, and Purpose. Ethics and Social Welfare, 4(2), 158-171.

Van der Meide, H., Leget, C., \& Olthuis, G. (2013). Giving Voice to Vulnerable People: The Value of Shadowing for Phenomenological Healthcare Research. Medicine, Health Care, and Philosophy, 16(4), 731-737.

Van der Meide, H., Olthuis, G., \& Leget, C. (2015). Feeling an Outsider Left in Uncertainty-A Phenomenological Study on the Experiences of Older Hospital Patients. Scandinavian Journal of Caring Sciences, 29(3), 528-536. 
Van Heijst, A. (2011). Professional Loving Care. An Ethical View of the Healthcare Sector. Leuven: Peeters.

Van Manen, M. (2014). Phenomenology of Practice. Walnut Creek: Left Coast Press.

Verghese, A. (2011). A Doctor's Touch. TED Talk. Retrieved June 1, 2016, from https://www.ted.com/talks/abraham_verghese_a_doctor_s_touch. Published 2011.

Visse, M. (2012). Openings for Humanization in Modern Health Care Practices. Unpublished dissertation. Amsterdam: Vrije Universiteit. https://research. vu.nl/ws/portalfiles/portal/682632.

Vosman, F., \& Baart, A. (2008). Aannemelijke Zorg Over Het Uitzieden En Verdringen van Praktische Wijsheid in de Gezondheidszorg. Den Haag: Lemma. Vosman, F., \& Baart, A. (2011). Relationship Based Care and Recognition. Part Two: Good Care and Recognition. In C. Leget, C. Gastmans, \& M. Verkerk (Eds.), Care, Compassion and Recognition: An EthicalDimension (pp. 201-228). Leuven: Peeters.

Williams, A. N., \& Irurita, V. (2004). Therapeutic and Non-therapeutic Interpersonal Interactions: The Patient's Perspective. Journal of Clinical Nursing, 13(7), 806-815.

Open Access This book is licensed under the terms of the Creative Commons Attribution 4.0 International License (http://creativecommons.org/licenses/ by/4.0/), which permits use, sharing, adaptation, distribution and reproduction in any medium or format, as long as you give appropriate credit to the original author(s) and the source, provide a link to the Creative Commons license and indicate if changes were made.

The images or other third party material in this chapter are included in the chapter's Creative Commons license, unless indicated otherwise in a credit line to the material. If material is not included in the chapter's Creative Commons license and your intended use is not permitted by statutory regulation or exceeds the permitted use, you will need to obtain permission directly from the copyright holder.

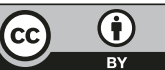

